\title{
Bioethanol from Paddy Straw: A Potential Feedstock for Substitution of Petroleum Based Fuel in Future
}

\author{
M.K.Ghosal $^{1 *}$ and JyotiRanjan Rath ${ }^{2}$ \\ ${ }^{1}$ Department of Farm Machinery and Power, College of Agricultural Engineering and \\ Technology, Odisha University of Agriculture and Technology, Bhubaneswar-751003, \\ Odisha, India \\ ${ }^{2}$ Research Scholar (Agricultural Economics), India
}

*Corresponding author

\begin{tabular}{|c|c|}
\hline & A B S T R A C T \\
\hline Keywords & \multirow{4}{*}{$\begin{array}{l}\text { Production of biofuels, especially bio-ethanol from lignocellulosic biomass, holds } \\
\text { remarkable potential to meet the current energy demand as well as to mitigate greenhouse } \\
\text { gas emissions for a sustainable clean environment. Rice is one of the most importan } \\
\text { agricultural crops in India. Rice straw is an important residue which is generated in large } \\
\text { amount in India. Every kilogram of grain harvesting is accompanied by the production of } \\
\text { rice straw to a tune of } 1.0-1.5 \mathrm{~kg} \text {. Major proportion of the rice straw is burnt in the fielc } \\
\text { itself. Burning of rice straw in the open fields leads to air pollution and also release } \\
\text { particulate matter into the atmosphere. In India } 23 \% \text { of rice straw residue produced is } \\
\text { surplus and the greenhouse gas emissions through open field burning constitute } 0.05 \% \\
\text { Hence, effective utilization of surplus rice straw residue in a sustainable manner with } \\
\text { respect to production of bio-ethanol is the need of hour to meet the fast depletion of } \\
\text { petroleum fuel and to protect the environment from their rampant practice of open field } \\
\text { burning after harvesting. This paper discusses in details the utilization of paddy straw, a } \\
\text { potential feed stock for substitution of petroleum based fuel in future. }\end{array}$} \\
\hline $\begin{array}{l}\text { Biofuel, Bio- } \\
\text { ethanol, } \\
\text { Lignocellulosic } \\
\text { biomass, Paddy } \\
\text { straw, Fermentation }\end{array}$ & \\
\hline Article Info & \\
\hline $\begin{array}{l}\text { Accepted: } \\
\text { xx July } 2019 \\
\text { Available Online: } \\
\text { xx August } 2019\end{array}$ & \\
\hline
\end{tabular}

\section{Introduction}

Energy security and climate change imperatives require large scale substitution of petroleum based fuel. Bioethanol, a substitute to fossil fuels not only reduces the reliance on oil import and alleviates uncertainties caused by the fluctuations of oil prices but also secure reduction in environmental pollution problems due to its high oxygen content
(Belal, 2013). The fermentative production of ethanol using the prevailing practices of starch and sugar based technology suffers from raw materials shortage and high cost. Therefore, a potential method for low cost fermentative production of ethanol is to utilize lignocellulosic materials (Abraham et al., 2016). The agricultural crop residue such as rice straw is one of the most abundant lignocellulosic wastes on the earth. About 1- 
$1.5 \mathrm{~kg}$ of straw is produced from every $\mathrm{kg}$ of grain harvested. The options for the disposal of rice straw are limited due to its low bulk density, slow degradation in soil, harbouring rice stem diseases and high mineral content (Goel and Wati, 2016). On farm burning of rice straw after harvesting is a usual practice followed in many parts of the country, leading to the pollution of air and causes health hazards like asthma and bronchitis among the human beings. Researchers suggest that open field burning of paddy straw contributes heavily towards production of harmful greenhouse gas (GHG) emissions including polycyclic aromatic hydrocarbons (PAHs), as well as polychlorinated dibenzo-p- dioxins (PCDDs), and polychlorinated dibenzofurans (PCDFs), referred to as dioxins. Experimentally, it has been evaluated that one tonne of paddy straw releases $3 \mathrm{~kg}$ particulate matter, $60 \mathrm{~kg} \mathrm{CO}, 1,460 \mathrm{~kg} \mathrm{CO}$, $199 \mathrm{~kg}$ ash, and $2 \mathrm{~kg} \mathrm{SO}$ (Jain et al., 2014). Local paddy straw burning affects the environment as these air pollutants have significant toxicological properties and are notably potential carcinogens. Paddy straw burning is at present a serious concern in India and has been driving the attention of policymakers and researchers.

In India, paddy is cultivated in about 43.95 million hectares producing about 106.54 million tonnes of rice and approximately 160 million tonnes of straw with a ratio of $1: 1.5$ for rice grain produced to straw produced (Anon 2016). Of the paddy straw produced, some part is used as a fuel for modern biomass power plants, brick kilns, cardboard making, mushroom cultivation, and some portion is used as fuel for domestic biomass cook stoves in rural areas. Portions of the paddy straw that remain uncollected in the fields due to a combined harvesting technology are burned in the field in order to quickly prepare the land ready for sowing of next crop. In Odisha, the current production of rice is 85 lakh tonnes and approximate production of rice straw is 100 lakh tonnes (Anon 2016). The bulk of the straw is used for fodder and other domestic purposes while as of now, there is no economic utilization of the rest of rice straw. Hence, rice straw is one of the abundant lignocellulosic biomass with potential as a feedstock for bioethanol production. To produce ethanol from the biomass biologically, enzymatic hydrolysis is necessary that can effectively degrade rice straw into fermentable sugars such as glucose and xylose. Consequently, the use of rice straw in ethanol production would be beneficial both in terms of environmental concerns, effective disposal and economic benefits to the farmers.

\section{Materials and Methods}

\section{Feedstocks for bioethanol}

Due to rapid growth in population and industrialization, worldwide, ethanol demand is increasing continuously. Conventional crops such as corn and sugarcane are unable to meet the global demand of bioethanol production due to their primary value of food and feed. Therefore, lignocellulosic substances such as agricultural wastes are attractive feed stocks for bioethanol production. Agricultural wastes are cost effective, renewable and abundant. Bioethanol from agricultural waste could be a promising technology though the process has several challenges and limitations such as biomass transport and handling and efficient pretreatment methods for total delignification of lignocellulosics. Proper pretreatment methods can increase concentrations of fermentable sugars after enzymatic saccharification, thereby improving the efficiency of the whole process. Conversion of glucose as well as xylose to ethanol needs some new fermentation technologies, to make the whole process cost effective. 
Lignocellulose is a complex carbohydrate polymer of cellulose, hemicellulose and lignin. Cellulose is linear and crystalline. It is a homopolymer of repeating sugar units of glucose linked by b-1,4glycosidic bonds. Hemicellulose is a short and highly branched polymer. It is a hetero-polymer of D-xylose, D-arabinose, D-glucose, D-galactose, and Dmannose. Lignin is hydrophobic in nature and istightly bound to these two carbohydrate polymers. It thus protects these polymers from microbial attack. It is a threedimensional aromatic polymer of $\mathrm{p}$, hydroxyl phenylpropanoid units connected by $\mathrm{CeC}$ and CeOeC links. Lignocellulosics are processed for bioethanol production through three major operations: pretreatment for delignification is necessary to liberate cellulose and hemicellulose before hydrolysis, hydrolysis of cellulose and hemicellulose to produce fermentable sugars including glucose, xylose, arabinose, galactose, mannose and fermentation of reducing sugars. The noncarbohydrate components of lignin also have value added applications.

Bioethanol feedstocks can be divided into three major groups: (1) First generation feedstocks (2) Second generation feedstocks and (3) Third generation feedstocks. First generation bioethanol feedstocks come from agricultural cereal and sugar crops that are also sources of human and animal food. The bioethanol produced by fermentation of sugars such as sugarcane, sugar beet, sorghum and molasses and starchy feedstocks such as grains viz. maize, wheat, root crops such as cassava are commonly known as first generation bioethanol.

Exploitation of first generation feedstocks for future bio-fuel production is ultimately unsustainable due to food security and landuse issues. Second-generation bioethanol refers to fuel alcohol produced from non-food biomass sources, such as lignocellulose, the most abundant form of carbon on the earth Polysaccharides present in lignocellulosic materials including cellulose and hemicellulose are of great interest as feedstocks for second generation ethanol production.

Third-generation biofuels are produced from algal biomass, which has a very distinctive growth yield as compared with classical lignocellulosic biomass. Microalgae have broad bioenergy potential as they can be used to produce liquid transportation and heating fuels, such as biodiesel and bioethanol. Microalgae provide carbohydrates (in the form of glucose, starch and other polysaccharides), proteins and lipids for the production of biofuels.

Out of the lignocellulosic biomasses, rice straw has the potential to produce bioethanol as it is a source that does not directly influence the price of the rice itself as a food source. It has several characteristics that make it a potential feedstock for fuel ethanol production. It has high cellulose and hemicellulose content that can be readily hydrolyzed into fermentable sugars. In terms of chemical composition, the straw predominantly contains cellulose $(32-47 \%)$, hemicellulose (19-27\%) and lignin (5-24\%). The pentoses are dominant in hemicellulose, in which xylose is the most important sugar (14.8-20.2\%). It has been estimated that $1 \mathrm{~kg}$ rice straw generally contains $390 \mathrm{~g}$ of cellulose. This amount is theoretically enough to produce $220 \mathrm{~g}$ or $283 \mathrm{ml}$ of ethanol, however considering the practically achievable best yield as $74 \%$, it could produce $208 \mathrm{ml}$ of ethanol from a cellulose content of $1 \mathrm{~kg}$ rice straw (Belal, 2013).

\section{Pre-treatment}

Rice straw is an attractive lignocellulosic material for bioethanol production since it is 
one of the most abundant renewable resources. The presence of high ash and silica content in rice straw makes it an inferior feedstock for ethanol production. One of the major challenges in developing technology for bioethanol production from rice straw is selection of an appropriate pre-treatment technique. The choice of pre-treatment methods plays an important role to increase the efficiency of enzymatic saccharification thereby making the whole process economically viable. The bioconversion of lignocellulosics to ethanol consists of two main processes: hydrolysis of lignocellulosic carbohydrate to fermentable reducing sugars and fermentation of the sugars to ethanol. The hydrolysis is usually catalyzed by cellulase enzymes and the fermentation is carried out by yeasts or bacteria. The presence of lignin and hemicellulose in lignocellulosic materials make the access of cellulase enzymes difficult, thus reducing the efficiency of the hydrolysis. Pretreatment of lignocellulosic biomass prior to hydrolysis can significantly improve the hydrolysis efficiency by removal of lignin and hemicellulose, reduction of cellulose crystallanity and increase of porosity.

Pretreatment methods can be broadly classified into three groups:

1. Physical: Employ the mechanical combination such as by a combination of chipping, grinding, and milling to reduce cellulose crystallinity or irradiation processes to change only the physical characteristics of biomass.

2. Chemical: The chemical processes employs acids $\left(\mathrm{H}_{2} \mathrm{SO}_{4}, \mathrm{HCl}\right.$, organic acids etc. $)$ or alkalis $\left(\mathrm{NaOH}, \mathrm{Na}_{2} \mathrm{CO}_{3}, \mathrm{Ca}(\mathrm{OH})_{2}, \mathrm{NH}_{3}\right.$ etc. $)$ or ozone gas. The acid treatment typically shows the selectivity towards hydrolyzing the hemicelluloses components, whereas alkalis have better selectivity for the lignin and various uronic acid substitutions on hemicellulose that lower the accessibility of enzyme to the hemicellulose and cellulose.

3. Biological: Microorganisms such as brown, white and soft-rot fungi are used in this treatment to degrade lignin and solubilize hemicellulose. White-rot fungi are the most effective biological pretreatment of lignocellulosic materials.

\section{Hydrolysis}

Hydrolysis is a process in which the carbohydrate polymers in lignocellulosic materials are converted to simple sugars before fermentation. There are various methods for the hydrolysis of lignocellulosic materials. The most commonly applied methods can be classified in two groups: chemical hydrolysis (dilute and concentrated acid hydrolysis) and enzymatic hydrolysis. There are some other hydrolysis methods in which no chemicals or enzymes are applied. For e.g., lignocelluloses may be hydrolyzed by gamma-ray or electron-beam irradiation or microwave irradiation. However, those processes are commercially unimportant. By the hydrolysis of lignocellulosic material, so many products are formed. Hemicelluloses are hydrolyzed to xylose, mannose, acetic acid, galactose, and glucose are liberated. Whereas cellulose and lignin are hydrolyzed to glucose and phenolics respectively. Mainly propionic acids, acetic acid, hydroxy1propanone, hydroxy-1-butanone and 2furfuraldeyde are formed due to degradation of xylan. Due to high temperature and pressure xylose used to further degrade into furfural while in case of hexose the main degradation product is 5-hydroxymethyl furfural(HMF). Both compounds affect the growth and metabolism of several microorganisms during metabolism (Demirbas 2005). Sarkar et al., (2012) found protein and RNA synthesis inhibition in 
Candida tropical is due to furfural. 5-HMF was also found to be an inhibitor of ethanol production by Saccharomyces cerevisiae.

\section{Chemical hydrolysis}

In chemical hydrolysis lignocellulosic materials are exposed to a chemical for a period of time at a specific temperature, chemical concentration, substrate concentration and results in sugar monomers from cellulose and hemicellulose polymers (Garima et al., 2015). In the chemical hydrolysis, the pretreatment and the hydrolysis may be carried out in a single step. Acids are predominantly used for chemical hydrolysis. There are two basic types of acid hydrolysis processes: dilute acid and concentrated acid. Dilute acid hydrolysis is used from past so many years for converting cellulose to glucose. High temperature and pressure are required for this process and also has a reaction time in the range of seconds or minutes. Dilute acid process involves a solution of about $1 \% \mathrm{H}_{2} \mathrm{SO}_{4}$ concentration in a continuous flow reactor at a high temperature (about $488 \mathrm{~K}$ ). Most dilute acid processes are limited to a sugar recovery efficiency of around $50 \%$. In comparison to dilute acid hydrolysis, concentrated acid hydrolysis leads to little sugar degradation and gives sugar yields approaching 100\%. The concentrated acid process offers more potential for cost reductions than the dilute acid process as it requires lower temperature and less time. However, environment and corrosion problems and the high cost of acid consumption and recovery creating major problem for its economic success.

\section{Enzymatic hydrolysis}

Acid hydrolysis has a major disadvantage where the sugars are converted to degradation products like furfural, hydroxyl furfural. This degradation can be prevented by using enzymes favouring $100 \%$ selective conversion of cellulose to glucose. Enzymatic hydrolysis involves enzymes for the degradation of cellulose and hemicellulose. Structural parameters of the substrate, such as lignin and hemicellulose content, surface area, and cellulose crystallinity hindered the enzymatic hydrolysis of cellulose and hemicellulose. Enzyme hydrolysis is usually conducted at mild conditions $(\mathrm{pH} 4.8)$ and temperature $(318-323 \mathrm{~K})$ and does not have a corrosion problem, this leads to its low utility cost as compared to acid or alkaline hydrolysis. The enzymatic hydrolysis has currently high yields $(75-85 \%)$ and improvements are still projected to (85-95\%). Enzymatic hydrolysis uses carbohydrate degrading enzymes (Cellulases and hemicellulases) for hydrolyzation of lignocelluloses into fermentable sugars.

\section{Fermentation}

Both six-carbon (hexoses) and five-carbon (pentose) sugars (if both cellulose and hemicellulose are hydrolyzed) are present in supernatant of enzymatic hydrolysis of lignocelluloses. Typically, glucose, xylose, arabinose, galactose, mannose, fucose, and rhamnose are present in the hydrolysate. The microorganisms should fulfil certain parameters in terms of their performance parameters and other requirements such as compatibility with existing products, processes and equipment for bioethanol fermentation.

\section{Environmental aspects}

Ethanol represents closed carbon dioxide cycle because after burning of ethanol, the released carbon dioxide is recycled back into plant material because plants use $\mathrm{CO}_{2}$ to synthesize cellulose during photosynthesis cycle. Ethanol production process only uses energy from renewable energy sources; no net 
carbon dioxide is added to the atmosphere, making ethanol an environmentally beneficial energy source. In addition, the toxicity of the exhaust emissions from ethanol is lower than that of petroleum sources. Ethanol derived from biomass is the only liquid transportation fuel that does not contribute to the greenhouse gas effect.

Regarding sustainability issues with bioethanol, it is apparent that fossil fuel combustion is contributing to an elevation of greenhouse gas (GHG) emissions (especially $\mathrm{CO}_{2}$ ) and consequentially is causing changes to the earth's climate. Road transport fuel combustion is currently responsible for around $20 \%$ of GHG emissions. The reduction of GHG pollution is the main advantage of utilizing biomass conversion into ethanol (Demirbas, 2008). Ethanol contains $35 \%$ oxygen that helps complete combustion of fuel and thus reduces particulate emission that pose health hazard to living beings. A study conducted by Abraham 2016 on the ethanol blended diesel (E10 and E30) combustion at different loads found that addition of ethanol to diesel fuel simultaneously decreases cetane number, high heating value, aromatics fractions and kinematic viscosity of ethanol blended diesel fuels and changes distillation temperatures. These factors lead to the complete burning of ethanol and less emissions. With its ability to reduce ozone precursors by $20-30 \%$, bioethanol can play a significant role in reducing the harmful gases in metro cities worldwide. Ethanol blended diesel (E-15) causes the $41 \%$ reduction in particulate matter and 5\% $\mathrm{NO}_{\mathrm{x}}$ emission (Sidhu et al., 2015). One of the disadvantages in using ethanol as fuel is that aldehyde predominantly acetaldehydes emissions are higher than those of gasoline. However, acetaldehydes emissions generate less adverse health effects in comparison to formaldehydes emitted from gasoline engines.
In conclusion, conversion of crop residues is essential for sustainable development. Rice straw offers a potential feed stock for the production of bioethanol and several value added products. Utilization of these residues improves the sustainability as well as reduces the negative impacts due to its disposal. Recent estimates of costs for biofuel production show that second generation biofuels are two to three times more expensive than petroleum fuels on an energy equivalent basis (Carriquiry et al., 2011). To bring down the production cost using biochemical platforms, several challenges need to be addressed to make the process economically and environmentally competitive. These challenges are in the areas of (i) feedstock production (ii) feed stock logistics (iii) development of energy efficient technologies (pretreatment, enzymatic hydrolysis, and microbial fermentation)(iv) co-products development (v) establishment of biofuel and biochemical standards (vi) biofuel distribution (vii) societal acceptance and (viii) environmental impact minimization. All of these challenging areas require expertise in various sectors like agronomy, biomass logistics, biomass conversion, process engineering, chemistry, conversion technology, genetic engineering, microbial fermentation, economics, and environmental science.

Lignocellulosic biomass has been projected to be one of the main resources for economically attractive bioethanol production. Though theoretical ethanol yields from sugar and starch (g ethanol/g substrate) are higher than from lignocellulose, these conventional sources are insufficient for worldwide bioethanol production. In that aspect agricultural wastes are renewable, less costly and abundantly available in nature. Agricultural wastes do not demand separate land, water, and energy requirements. They do not have food value as well. For economically 
feasible bioethanol production, several hindrances are to be overcome. These refer to the four major aspects which are feedstock, conversion technology, hydrolysis process, and fermentation configuration. With regard to feedstock, major obstacles are cost, supply, harvesting, and handling. As regards conversion technology, the hindrances are biomass processing, proper and cost effective pretreatment technology to liberate cellulose and hemicellulose from their complex with lignin. In respect of the hydrolysis process the challenge is to achieve an efficient process for depolymerization of cellulose and hemicelluloses to produce fermentable monomers with high concentration. In this aspect, enzymatic hydrolysis may be the most potent alternative process for saccharification of complex polymer. Several efforts have been made to reduce the cost of cellulase enzyme to optimize the enzymatic hydrolysis process. Finally, in case of fermentation configuration, the challenges involved are xylose and glucose co-fermentation, and the use of recombinant microbial strains. In conclusion, it may be said that to solve the technology bottlenecks of the conversion process, novel science and efficient technology are to be applied, so that bioethanol production from agricultural wastes particularly the abundant availability of rice straw may be successfully developed and optimized in the near future.

\section{References}

Amith, Abraham, Anil, Kuruvilla, Raveendran, Sindhu, Pandey, Ashok and Parameswaran, Binod. 2016. Potential of rice straw for bio-refining. Bioresource Technology 215: 29-36.

Anonymous. 2016. Agricultural Statistics, Govt. of India, New Delhi.

Annu, Goel and Leela, Wati. 2016. Ethanol production from rice (Oryza sativa) straw by simultaneous Saccharification and cofermentation. Indian Journal of Experimental Biology. Vol. 54, pp. 525-529.

Belal, E.B. 2013. Bioethanol production from rice straw residues. Braz. J. Microbiol. 44, 225-234.

Carriquiry, M.A., Du, X, and Timilsina, G.R. 2011. Second generation biofuels: economics and policies. Energy Policy $39,4222-4234$.

Demirbas, A. 2005. Bioethanol from cellulosic materials: a renewable motor fuel from biomass. Energy Sources. 27: 327-333.

Demirbas, A. 2008. Products from lignocellulosic materials via degradation processes, Energy Source A, 30, 27-37.

Jain, Niveta, Bhatia, Arti, and Pathak, Himanshu. 2014. Emission of Air Pollutants from Crop Residue Burning in India. Aerosol and Air Quality Research, 14: 422-430.

Sarkar, Nibedita, Ghosh, Sumanta Kumar, Banerjee, Satarupa and Aikat Kaustav. 2012. Bioethanol production from agricultural wastes: An overview. Renewable Energy, 37, 19-27.

Sidhu, Ruby, Bansal, Manjeet, Bath, Gurprit Singh and Garg, Rishav. 2015. Impact of Stubble Burning on the Ambient Air Quality. International Journal of Mechanical and Production Engineering, ISSN: 2320-2092. Volume- 3, Issue-10, Oct.-2015.

Tiwari Garima, Shivangi, Sharma Satyawati and Prasad Rajendra. 2015. Bioethanol Production: Future Prospects from Non-traditional Sources in India. International Journal of Research in Biosciences Vol. 4 Issue 4, pp. (1-15), October 2015. 


\section{How to cite this article:}

Ghosal, M.K. and JyotiRanjan Rath. 2019. Bioethanol from Paddy Straw: A Potential Feedstock for Substitution of Petroleum Based Fuel in Future. Int.J.Curr.Microbiol.App.Sci. 8(08): 1709-1716. doi: https://doi.org/10.20546/ijcmas.2019.808.202 